\title{
PENGARUH DOSIS PUPUK NPK MUTIARA TERHADAP PERTUMBUHAN DAN HASIL TANAMAN KACANG HIJAU
}

(Phaseolus radiatus L.)

\author{
Murdaningsih ${ }^{1}$, Alexander Boro Kramat ${ }^{2}$ \\ Ningsih_murda@yahoo.co.id
}

Program Studi Agroteknologi, Fakultas Pertanian-Universitas Flores

\begin{abstract}
This study aims to determine the effect of NPK Mutiara fertilizer dose on the growth and yield of green beans and determine the optimum dosage of NPK Mutiara fertilizer that can deliver growth and yield optimal green beans.

The design used in this study is a randomized block design with treatments used were N0 (without fertilizer NPK NPK $0 \mathrm{~kg} \mathrm{ha}^{-1}$ or $0 \mathrm{~g} \mathrm{plot}^{-1}$ ), N1 (NPK fertilizer $125 \mathrm{~kg} \mathrm{ha}^{-1}$ or $25 \mathrm{~g} \mathrm{plot}^{-}$ ${ }^{1}$ ), N2 (NPK fertilizer $250 \mathrm{~kg} \mathrm{ha}^{-1}$ or $50 \mathrm{~g} \mathrm{plot}^{-1}$ ), N3 (NPK fertilizer $375 \mathrm{~kg}$ ha-1 or $75 \mathrm{~g}$ ), N4 (NPK $500 \mathrm{~kg} \mathrm{ha}^{-1}$ or $100 \mathrm{~g} \mathrm{plot}^{-1}$ ). Variable observation in this study were plant height, number of leaves, leaf area, number of pods $\tan ^{-1}$ fresh weight stover tan-1, the dry weight of stover tan1 , the dry weight of stover ha-1 dry weight of seed tan-1, heavy ha-1 dry beans, dry weight of 100 seeds.

The results showed that treatment of NPK fertilizer dose of $500 \mathrm{~kg} \mathrm{ha}^{-1}$ very significant effect on plant height of $27.75 \mathrm{~cm}$, leaf number 8 strands, leaf area $357.78 \mathrm{~cm} 2$, Total pods 19.65 , fresh weight stover tan-1 96, $25 \mathrm{~g}$, dry weight of stover tan-1 $76.00 \mathrm{~g}$, stover dry weight ha-1 19.00 tons, dry weight of seed tan-1 5.36 gram dry weight seed ha-1 1.34 tonnes, weight of 100 seeds 2.62 gr.

Keywords: Dose, NPK Mutiara fertilizer, green beans

\section{Latar belakang}

Tanaman kacang hijau (Phaseolus

radiatus L.) merupakan salah satu tanaman

Leguminosae yang umum dibudidayakan di

Indonesia. Kacang hijau menduduki tempat

ketiga setelah kedelai dan kacang tanah.

Tanaman kacang hijau berpotensi untuk

dikembangkan karena nilai ekonomi tinggi

dan masih memberikan peluang pasar yang besar dan telah lama digunakan untuk pangan berupa bubur kacang hijau dan sayur (touge), serta brangkasannya untuk pakan ternak.

Berdasarkan data Nasional, luas panen kacang hijau pada tahun 2011 mencapai 297.315 ha dengan volume produksi
\end{abstract}


Murdaningsih: Pengaruh dosis pupuk npk mutiara terhadap pertumbuhan dan hasil tanaman kacang hijau (Phaseolus radiatus L.)

341.342 ton dan produktivitasnya 1,14 ton ha $^{-1}$. Produksi kacang hijau NTT sebesar 10.407 ton dengan luas panen 12.307 ha dan produktivitas 0,84 ton $\mathrm{ha}^{-1}$, sedangkan di kabupaten Ende pada tahun 2011 produksinya 268,1 ton dengan luas lahan 209 ha, menghasilkan produktivitas 1,28 ton ha $^{-1}$ (BPS 2013). Dari data tersebut menunjukan bahwa produktivitas kacang hijau di kabupaten Ende lebih tinggi dibandingkan dengan produktivitas kacang hijau ditingkat propinsi namun demikian produktivitas kacang hijau di kabupaten Ende belum mencapai standar produktivitas Nasional yaitu 1,6 ton $\mathrm{ha}^{-1}$ (BPTP 2012). Penyebab rendahnya produksi kacang hijau disebabkan karena kurang optimalnya teknik budidaya khusus tentang penggunaan pupuk. Salah satu cara untuk mengatasi masalah tersebut harus melakukan pemupukan yang tepat.

Marzuki, R. dan Soeprapto, H. S, (2007) menyatakan bahwa kacang hijau sangat membutuhkan unsur $\mathrm{N}, \mathrm{P}$ dan $\mathrm{K}$ dalam jumlah yang cukup yaitu $300 \mathrm{~kg} \mathrm{~N}$, $100 \mathrm{~kg} \mathrm{P}$ dan $100 \mathrm{~kg} \mathrm{~K}$ dan hal tersebut dapat dipenuhi melalui usaha pemupukan. Pupuk NPK merupakan pupuk majemuk dengan kandungan unsur hara yang lengkap. Pupuk NPK Mutiara mempunyai kandungan unsur hara $\mathrm{N} 16 \%$, P $16 \%$ dan $\mathrm{K} 16 \%$. Tumbuhan dapat tumbuh dengan baik dan sempurna apabila unsur-unsur yang diperlukan oleh tumbuhan tersebut terpenuhi (Saifudin, 2007).

Manfaat pupuk NPK yaitu menjadikan tanaman lebih hijau dan segar, merangsang pertumbuhan akar sehingga tanaman menjadi lebih sehat dan kuat, menjadikan batang tanaman lebih kuat dan tegak sehingga tidak mudah rebah, meningkatkan daya tahan terhadap serangan hama penyakit dan memperbesar buah, biji-bijian dan umbi (Sutedjo, 2011). Keunggulan pupuk NPK mmutiara yakni lebih mudah dalam penggunaannya karena 
Murdaningsih: Pengaruh dosis pupuk npk mutiara terhadap pertumbuhan dan hasil tanaman kacang hijau (Phaseolus radiatus L.)

tidak perlu menambahkan pupuk lain dan

kandungan unsur haranya lebih lengkap dan

seimbang. Hasil penelitian Adisarwanto

(2000) menyatakan bahwa penggunaan

pupuk NPK Mutiara $250 \mathrm{~kg} \mathrm{ha}^{-1}$ dapat

meningkatkan berat kering kacang tanah 1,8

ton ha dibanding dengan tanpa

menggunakan pupuk NPK Mutiara.

Berdasarkan uraian di atas, maka penulis perlu melakukan penelitian tentang

Pengaruh Dosis Pupuk NPK Mutiara

Terhadap Pertumbuhan dan Hasil

Tanaman Kacang Hijau (Phaseolus

radiatus L.).

\section{METODELOGI PENELITIAN}

\section{Tempat dan Waktu}

Penelitian ini dilakukan di kebun percobaan Fakultas Pertanian Universitas Flores, Desa lokoboko, Kecamatan Ndona, Kabupatan Ende. Ketinggian tempat 500 m dpl, curah hujan rata-rata 1508-2750 mm, suhu rata-rata 27,45-31. C, dengan hasil analisis awal $\mathrm{pH} 5,7, \mathrm{C}-1,37, \mathrm{~N}$ total
$0,15 \%, \mathrm{P}$ tersedia $17,25 \mathrm{ppm}, \mathrm{K}$ tersedia 161,75 ppm, pasir 54,04\%, debu 36,36\%, liat $9,60 \%$ dan jenis tanah lempung berpasir (Tage,2012). Waktu percobaan dilaksanakan pada bulan November 2013 sampai bulan Januari 2014.

\section{Bahan dan Alat}

Bahan yang digunakan dalam penelitian ini mencakup benih kacang hijau varietas No.129, pupuk NPK Mutiara, air untuk penyiraman. Sedangkan peralatan yang digunakan saat penelitian yaitu parang, cangkul, sekop, tugal, gembor, ember timbangan, meteran, tali rafia, patok ,pisau dan alat tulis.

\section{Rancangan Penelitian}

Penelitian ini dilakukan dengan menggunakan rancangan acak kelompok (RAK) dengan pola faktor tunggal yang terdiri dari 5 perlakuan yaitu :

NO $=0 \mathrm{~kg}$ NPK Mutiara $\mathrm{ha}^{-1}$ atau tanpa pupuk NPK Mutiara 
Murdaningsih: Pengaruh dosis pupuk npk mutiara terhadap pertumbuhan dan hasil tanaman kacang hijau (Phaseolus radiatus L.)

$\mathrm{N} 1=125 \mathrm{~kg}$ NPK Mutiara ha ${ }^{-1}$ atau $25 \mathrm{~g}$

$\operatorname{petak}^{-1}$

$\mathrm{N} 2=250 \mathrm{~kg}$ NPK Mutiara $\mathrm{ha}^{-1}$ atau $50 \mathrm{~g}$

$\operatorname{petak}^{-1}$

N3 = $375 \mathrm{~kg}$ NPK Mutiara $\mathrm{ha}^{-1}$ atau $75 \mathrm{~g}$

$\operatorname{petak}^{-1}$

$\mathrm{N} 4=500 \mathrm{~kg}$ NPK Mutiara $\mathrm{ha}^{-1}$ atau $100 \mathrm{~g}$

$\operatorname{petak}^{-1}$

Setiap perlakuan diulang sebanyak 4 kali sehingga secara keseluruhan terdapat 20 petak percobaan.

Pelaksanaan Penelitian

Persiapan Lahan

Lahan di bersihkan semua dari sisa tanaman yang masih ada agar memudahkan dalam pengolahan tanah. Tanah diolah dengan menggunakan cangkul sedalam kurang lebih $40 \mathrm{~cm}$ agar gembur, kemudian dibuat bedengan dengan ukuran $2 \mathrm{~m} \times 1 \mathrm{~m}$. Tinggi bedengan $30 \mathrm{~cm}$, jarak antara petak $50 \mathrm{~cm}$ dan langsung dijadikan saluran drainase, jarak antara ulangan $50 \mathrm{~cm}$.

\section{Variabel Pengamatan}

Variabel Pertumbuhan dalam penelitian ini adalah Tinggi tanaman (cm), Jumlah daun $\tan ^{-1}$ (helai), Luas daun $\left(\mathrm{cm}^{2}\right)$, sedangkan variabel hasil adalah Jumlah polong $\tan ^{-1}$, Berat segar berangkasan $\tan ^{-1}$ (g), Berat kering brangkasan $\tan ^{-1}$, Berat kering brangkasan $\mathrm{ha}^{-1}$, Berat kering biji tan ${ }^{-}$ ${ }^{1}(\mathrm{~g})$, Berat kering biji ha ${ }^{-1}$, dan Berat kering 100 biji (g).

\section{Penanaman}

Sehari sebelum penanaman, bedengan disiram sampai cukup lembab. Penanaman dilakukan secara tugal pada kedalaman $4 \mathrm{~cm}$ dan jarak tanam $40 \mathrm{~cm}$ x $20 \mathrm{~cm}$ sehingga pada setiap petak percobaan terdapat 50 tanaman. Benih dimasukan ke dalam lubang tanam sebanyak 4 biji per lubang dan setelah tumbuh dijarangkan dengan mempertahankan 2 tanaman per lubang.

\section{Pemberian Pupuk NPK}

Pupuk NPK diberikan dengan melarutkan dalam air sebanyak 5 liter setiap perlakuan dan diberikan disekitar tanaman . 
Murdaningsih: Pengaruh dosis pupuk npk mutiara terhadap pertumbuhan dan hasil tanaman kacang hijau (Phaseolus radiatus L.)

Pemberian dilakukan dua kali yaitu pada umur 7 hst dan 35 hst dengan setengah dari dosis setiap perlakuan. $\mathrm{N} 0=0 \mathrm{~kg}$ NPK Mutiara $\mathrm{ha}^{-1}$ atau tanpa pupuk NPK Mutiara, N1 = $125 \mathrm{~kg}$ NPK Mutiara ha ${ }^{-1}$ atau $25 \mathrm{~g} \mathrm{petak}^{-1}, \mathrm{~N} 2=250 \mathrm{~kg}$ NPK Mutiara $\mathrm{ha}^{-1}$ atau $50 \mathrm{~g} \mathrm{petak}^{-1}, \mathrm{~N} 3=375 \mathrm{~kg}$ NPK Mutiara $\mathrm{ha}^{-1}$ atau $75 \mathrm{~g} \mathrm{petak}^{-1}, \mathrm{~N} 4=500 \mathrm{~kg}$ NPK Mutiara ha ${ }^{-1}$ atau $100 \mathrm{~g}_{\text {petak }}{ }^{-1}$.

\section{Panen}

Panen tanaman kacang hijau dilakukan pada pagi hari dan dilakukan satu kali. Tanaman kacang hijau dalam petak percobaan akan dipanen setelah pertumbuhannya menunjukan tanda- tanda yaitu berubahnya warna polong dari hijau menjadi hitam atau coklat dan kering dan umur panen kacang hijau umumnya 60 hari.

\section{Analisis Data}

Data hasil pengamatan dianalisis dengan analisis sidik ragam. Apabila perlakuan berpengaruh nyata atau sangat nyata terhadap variabel yang diamati, maka dilanjutkan dengan uji BNT 5\% (Gomez dan Gomez, 1995).

\section{HASIL DAN PEMBAHASAN}

\section{Hasil}

Hasil analisis statistik menunjukan bahwa pemberian dosis pupuk NPK Mutiara terhadap pertumbuhan dan hasil tanaman kacang hijau berpengaruh sangat nyata pada semua variabel pengamatan. 
Murdaningsih: Pengaruh dosis pupuk npk mutiara terhadap pertumbuhan dan hasil tanaman kacang hijau (Phaseolus radiatus L.)

Tabel 4.1 Signifikasi Pengaruh Perlakuan Dosis Pupuk NPK Mutiara Terhadap Pertumbuhan dan Hasil Tanaman Kacang Hijau

\begin{tabular}{|c|c|}
\hline Variabel & Signifikasi \\
\hline \multicolumn{2}{|l|}{ Tinggi tanaman $\tan ^{-1}(\mathrm{~cm})$} \\
\hline 14 Hst & $* *$ \\
\hline $21 \mathrm{Hst}$ & $* *$ \\
\hline $28 \mathrm{Hst}$ & $* *$ \\
\hline \multicolumn{2}{|l|}{ Jumlah daun $\tan ^{-1}$ (helai) } \\
\hline 14 Hst & $* *$ \\
\hline $21 \mathrm{Hst}$ & $* *$ \\
\hline $28 \mathrm{Hst}$ & $* *$ \\
\hline \multicolumn{2}{|l|}{ Luas daun $\tan ^{-1}$} \\
\hline 14 Hst & $* *$ \\
\hline $21 \mathrm{Hst}$ & $* *$ \\
\hline 28 Hst & $* *$ \\
\hline Jumlah polong $\tan ^{-1}$ (polong) & $* *$ \\
\hline Berat segar brangkasan $\tan ^{-1}(\mathrm{~g})$ & $* *$ \\
\hline Berat kering brangkasan $\tan ^{-1}(\mathrm{~g})$ & $* *$ \\
\hline Berat kering brangkasan $\mathrm{ha}^{-1}(\mathrm{t})$ & $* *$ \\
\hline Berat kering biji $\tan ^{-1}(\mathrm{~g})$ & $* *$ \\
\hline Berat kering biji ha ${ }^{-1}(\mathrm{t})$ & $* *$ \\
\hline Berat kering 100 biji (g) & $* *$ \\
\hline
\end{tabular}

\section{Pembahasan}

\section{Variabel Pertumbuhan}

Hasil analisis sidik ragam menunjukan bahwa dosis pupuk NPK Mutiara memberikan pengaruh yang sangat nyata terhadap tinggi tanaman, jumlah daun dan luas daun tanaman kacang hijau.

Perlakuan dosis pupuk NPK Mutiara memberikan pengaruh terhadap variabel pertumbuhan pada setiap perlakuan dimana, pada perlakuan dosis N0 (0 kg/ha) ke N1 $(125 \mathrm{~kg} / \mathrm{ha})$ meningkatkan rataan total tinggi tanaman, jumlah daun dan luas daun sebesar $15,63 \%, 4,29 \%, 8,13 \%$; pada perlakuan dosis N1 (125 kg/ha) ke N2 (225 kg/ha) rataan total tinggi tanaman, jumlah daun dan luas daun sebesar3,47\%, 4,10\%, 6,12\%; pada perlakuan dosis N2 $(250 \mathrm{~kg} / \mathrm{ha}) \mathrm{ke} \mathrm{N} 3$ (375 kg/ha) rataan total tinggi tanaman, 
Murdaningsih: Pengaruh dosis pupuk npk mutiara terhadap pertumbuhan dan hasil tanaman kacang hijau (Phaseolus radiatus L.)

jumlah daun dan luas daun sebesar 2,48\%, 4,07\%, 5,33\%; dan pada perlakuan dosis N3 (375 kg/ha ) ke N4 (500 kg/ha) rataan total tinggi tanaman, jumlah daun dan luas daun sebesar1,69\%, 3,23\%, 6,50\%; hal ini menunjukan bahwa semakin tinggi peningkatan dosis pupuk NPK Mutiara, maka semakin banyak unsur hara yang diserap oleh tanaman kacang hijau sehingga pertumbuhan tanaman semakin meningkat. Hasil penelitian menunjukan bahwa hipotesis yang pertama (1) terbukti dengan peningkatan variabel pertumbuhan pada setiap perlakuan dosis pupuk NPK yang diberikan pada tanaman kacang hijau.

Tabel 4.2 Pengaruh Dosis Pupuk NPK Mutiara Terhadap Tinggi Tanaman, Jumlah Daun, Luas Daun Tanaman Kacang Hijau

VARIABEL PERLAKUAN

UMUR TANAMAN

\begin{tabular}{ccccc}
\hline & & $14 \mathrm{HST}$ & $21 \mathrm{HST}$ & $28 \mathrm{HST}$ \\
\hline TINGGI & $\mathrm{NO}$ & $12,28 \mathrm{e}$ & $18,55 \mathrm{e}$ & $22,60 \mathrm{e}$ \\
TANAMAN & $\mathrm{N} 1$ & $14,95 \mathrm{~d}$ & $22,33 \mathrm{~d}$ & $25,71 \mathrm{~d}$ \\
$(\mathrm{~cm})$ & $\mathrm{N} 2$ & $15,53 \mathrm{c}$ & $22,90 \mathrm{c}$ & $26,83 \mathrm{c}$ \\
& $\mathrm{N} 3$ & $16,13 \mathrm{~b}$ & $23,27 \mathrm{~b}$ & $27,41 \mathrm{~b}$ \\
& $\mathrm{~N} 4$ & $16,49 \mathrm{a}$ & $23,66 \mathrm{a}$ & $27,75 \mathrm{a}$ \\
\hline & BNT $5 \%$ & 0,16 & 0,13 & 0,10 \\
\hline \multirow{2}{*}{ JUMLAH } & $\mathrm{NO}$ & $3,00 \mathrm{e}$ & $5,00 \mathrm{e}$ & $7,00 \mathrm{e}$ \\
DAUN & $\mathrm{N} 1$ & $3,20 \mathrm{~d}$ & $5,20 \mathrm{~d}$ & $7,20 \mathrm{~d}$ \\
(helai) & $\mathrm{N} 2$ & $3,40 \mathrm{c}$ & $5,40 \mathrm{c}$ & $7,40 \mathrm{c}$ \\
& $\mathrm{N} 3$ & $3,50 \mathrm{~b}$ & $5,75 \mathrm{~b}$ & $7,65 \mathrm{~b}$ \\
& $\mathrm{~N} 4$ & $3,60 \mathrm{a}$ & $5,90 \mathrm{a}$ & $8,00 \mathrm{a}$ \\
\hline \multirow{2}{*}{ LUAS } & BNT 5\% & 0,04 & 0,06 & 0,06 \\
\hline DAUN & $\mathrm{NO}$ & $37.12 \mathrm{e}$ & $124.15 \mathrm{e}$ & $289.67 \mathrm{e}$ \\
(cm2) & $\mathrm{N} 1$ & $41.81 \mathrm{~d}$ & $135.81 \mathrm{~d}$ & $303.58 \mathrm{~d}$ \\
& $\mathrm{~N} 2$ & $45.17 \mathrm{c}$ & $145.76 \mathrm{c}$ & $316.51 \mathrm{c}$ \\
\hline & $\mathrm{N} 3$ & $47.53 \mathrm{~b}$ & $155.72 \mathrm{~b}$ & $331.87 \mathrm{~b}$ \\
\hline & $\mathrm{N} 4$ & $49.75 \mathrm{a}$ & $168.90 \mathrm{a}$ & $357.78 \mathrm{a}$ \\
\hline
\end{tabular}

Keterangan : angka-angka yang diikuti oleh huruf yang sama pada kolom yang sama menunjukan pengaruh yang tidak berbeda nyata pada taraf uji BNT 5\% 
Murdaningsih: Pengaruh dosis pupuk npk mutiara terhadap pertumbuhan dan hasil tanaman kacang hijau (Phaseolus radiatus L.)

Sedangkan pada hipotesis ke-2 $\left(250 \mathrm{~kg} \mathrm{ha}^{-1}\right.$ tidak terbukti karena pada dosis pupuk NPK Mutiara $500 \mathrm{~kg} \mathrm{ha}^{-1}$ yang memberikan pertumbuhan tanaman kacang hijau yang baik. Hal ini menunjukkan bahwa hipotesis yang kedua (N2) tidak terbukti karena dosis tersebut belum mencukupi bagi pertumbuhan tanaman kacang hijau, karena kandungan hara yang terdapat pada pupuk NPK mutiara adalah nitrogen $16 \%$, posfor $16 \%$, dan kalium $16 \%$, jadi dosis pupuk NPK mutiara $250 \mathrm{~kg} \mathrm{ha}^{-1}$ setara dengan 40 kg N, 40 kg P, 40 kg K, karena kebutuhan hara untuk tanaman kacang hijau $300 \mathrm{~kg} \mathrm{~N}$, $100 \mathrm{~kg}$ P dan $100 \mathrm{~kg} \mathrm{~K}$ (Marzuki, R. dan Soeprapto, H.S. 2007) sehingga dosis pupuk NPK mutiara $250 \mathrm{~kg} \mathrm{ha}^{-1}$ belum mencukupi kebutuhan tanaman kacang hijau. Jika dibandingkan dengan dosis pupuk NPK mutiara $500 \mathrm{~kg} \mathrm{ha}^{-1}$ setara dengan $80 \mathrm{~kg} \mathrm{~N}$, $80 \mathrm{~kg} \mathrm{P}, 80 \mathrm{~kg} \mathrm{~K}$ menunjukan pertumbuhan yang terbaik, tetapi masih memungkinkan dosisnya ditingkatkan mengingat masih dibawah kebutuhan hara tanaman kacang hijau.

Pupuk NPK merupakan pupuk majemuk dengan kandungan unsur hara yang lengkap. Tumbuhan dapat tumbuh dengan baik dan sempurna apabila unsur-unsur yang diperlukan oleh tumbuhan tersebut terpenuhi (Saifudin, 2007).

Marzuki, R. dan Soeprapto, H. S, (2007) menyatakan bahwa kacang hijau sangat membutuhkan unsur $\mathrm{N}, \mathrm{P}$ dan $\mathrm{K}$ dalam jumlah yang cukup. Tanaman mengandung cukup $\mathrm{N}$ akan menunjukkan warna daun hijau tua yang artinya kadar klorofil dalam daun tinggi. Sebaliknya apabila tanaman kekurangan atau defisiensi $\mathrm{N}$ maka daun akan menguning (klorosis) karena kukarangan klorofil. Pertumbuhan tanaman lambat, lemah dan tanaman menjadi kerdil juga bisa disebabkan oleh kekurangan $\mathrm{N}$. Phosfor meningkatkan kualitas buah, 
Murdaningsih: Pengaruh dosis pupuk npk mutiara terhadap pertumbuhan dan hasil tanaman kacang hijau (Phaseolus radiatus L.)

sayuran, biji-bijian dan sangat penting dalam

pembentukan biji. Fosfor membantu

mempercepat perkembangan akar dan

perkecambahan, dapat meningkatkan

efisiensi penggunaan air, meningkatkan

daya tahan terhadap penyakit yang akhirnya

meningkatkan kualitas hasil panen. Gejala

pertama tanaman yang kekurangan $\mathrm{P}$ adalah tanaman berfungsi sebagai aktivator dari banyak enzim yang berpartisipasi dalam beberapa proses metabolisme utama tanaman.

\section{Variabel hasil}

Berdasarkan hasil analisis sidik ragam pemberian pupuk NPK Mutiara berpengaruh sangat nyata terhadap variabel hasil.

tanaman menjadi kerdil. $\mathrm{K}$ di dalam

Tabel 4.3 Pengaruh Dosis Pupuk NPK Mutiara Terhadap Tinggi Tanaman, Jumlah Daun, Luas Daun Tanaman Kacang Hijau

\begin{tabular}{ccccc}
\hline VARIABEL & PERLAKUAN & \multicolumn{3}{c}{ UMUR TANAMAN } \\
\hline & & $14 \mathrm{HST}$ & $21 \mathrm{HST}$ & $28 \mathrm{HST}$ \\
\hline TINGGI & $\mathrm{NO}$ & $12,28 \mathrm{e}$ & $18,55 \mathrm{e}$ & $22,60 \mathrm{e}$ \\
TANAMAN & $\mathrm{N} 1$ & $14,95 \mathrm{~d}$ & $22,33 \mathrm{~d}$ & $25,71 \mathrm{~d}$ \\
$(\mathrm{~cm})$ & $\mathrm{N} 2$ & $15,53 \mathrm{c}$ & $22,90 \mathrm{c}$ & $26,83 \mathrm{c}$ \\
& $\mathrm{N} 3$ & $16,13 \mathrm{~b}$ & $23,27 \mathrm{~b}$ & $27,41 \mathrm{~b}$ \\
& $\mathrm{~N} 4$ & $16,49 \mathrm{a}$ & $23,66 \mathrm{a}$ & $27,75 \mathrm{a}$ \\
\hline & BNT 5\% & 0,16 & 0,13 & 0,10 \\
\hline \multirow{3}{*}{ JUMLAH } & $\mathrm{NO}$ & $3,00 \mathrm{e}$ & $5,00 \mathrm{e}$ & $7,00 \mathrm{e}$ \\
DAUN & $\mathrm{N} 1$ & $3,20 \mathrm{~d}$ & $5,20 \mathrm{~d}$ & $7,20 \mathrm{~d}$ \\
(helai) & $\mathrm{N} 2$ & $3,40 \mathrm{c}$ & $5,40 \mathrm{c}$ & $7,40 \mathrm{c}$ \\
& $\mathrm{N} 3$ & $3,50 \mathrm{~b}$ & $5,75 \mathrm{~b}$ & $7,65 \mathrm{~b}$ \\
& $\mathrm{~N} 4$ & $3,60 \mathrm{a}$ & $5,90 \mathrm{a}$ & $8,00 \mathrm{a}$ \\
\hline & BNT 5\% & 0,04 & 0,06 & 0,06 \\
\hline \multirow{2}{*}{ LUAS } & NO & $37.12 \mathrm{e}$ & $124.15 \mathrm{e}$ & $289.67 \mathrm{e}$ \\
DAUN & $\mathrm{N} 1$ & $41.81 \mathrm{~d}$ & $135.81 \mathrm{~d}$ & $303.58 \mathrm{~d}$ \\
(cm2) & $\mathrm{N} 2$ & $45.17 \mathrm{c}$ & $145.76 \mathrm{c}$ & $316.51 \mathrm{c}$ \\
& $\mathrm{N} 3$ & $47.53 \mathrm{~b}$ & $155.72 \mathrm{~b}$ & $331.87 \mathrm{~b}$ \\
\hline & $\mathrm{N} 4$ & $49.75 \mathrm{a}$ & $168.90 \mathrm{a}$ & $357.78 \mathrm{a}$ \\
\hline
\end{tabular}

Keterangan : angka-angka yang diikuti oleh huruf yang sama pada kolom yang sama menunjukan pengaruh yang tidak berbeda nyata pada taraf uji BNT 5\% 
Murdaningsih: Pengaruh dosis pupuk npk mutiara terhadap pertumbuhan dan hasil tanaman kacang hijau (Phaseolus radiatus L.)

Pada perlakuan dosis N0 (0 kg/ha) ke N1

(125 kg/ha) meningkatkan rataan total jumlah polong 7,27\%, berat segar brangkasan $\tan ^{-1} 16,15 \%$, berat kering brangkasan $\tan ^{-1} 21,56 \%$, berat kering brangkasan ha ${ }^{1} 21,56 \%$ berat kering biji $\tan ^{-1}$ $21,15 \%$, berat kering biji ha ${ }^{-1} 21,15 \%$, berat 100 biji sebesar 19,40\%; dosis N1 (125 $\mathrm{kg} / \mathrm{ha}) \mathrm{ke} \mathrm{N} 2(250 \mathrm{~kg} / \mathrm{ha})$ meningkatkan rataan total jumlah polong $10,43 \%$, berat segar brangkasan $\tan ^{-1} 12,70 \%$, berat kering brangkasan $\tan ^{-1} 14,75 \%$, berat kering brangkasan ha ${ }^{1} 14,75 \%$, berat kering biji $\tan ^{-}$ ${ }^{1} 11,96 \%$ berat kering biji ha ${ }^{-1} 11,96 \%$, berat 100 biji 10,81\%; dosis N2 (250 kg/ha) ke N3 $(375 \mathrm{~kg} / \mathrm{ha})$ meningkatkan rataan total jumlah polong 9,71 berat segar brangkasan $\tan ^{-1} 5,57 \%$, berat kering brangkasan $\tan ^{-1}$ $7,33 \%$, berat kering brangkasan ha ${ }^{1} 7,33 \%$, berat kering biji $\tan ^{-1} 10,66 \%$, berat kering biji ha ${ }^{-1} 10,66 \%$, berat 100 biji $11,83 \%$; dosis N3 (375 kg/ha) ke N4 (500 kg/ha) meningkatkan rataan total jumlah polong
$6,10 \%$, berat segar brangkasan $\tan ^{-1} 5,71 \%$, berat kering brangkasan $\tan ^{-1} 6,25 \%$, berat kering brangkasan ha $^{1} 6,25 \%$, berat kering biji $\tan ^{-1} 5,41 \%$, berat kering biji ha-1 $5,41 \%$, berat 100 biji 7,25 \%. Perlakuan pemberian dosis pupuk NPK mutiara sebanyak $500 \mathrm{~kg} \mathrm{ha}^{-1}$ atau perlakuan (N4) menunjukan jumlah polong, berat segar brangkasan $\tan ^{-1}$, berat kering brangkasan $\tan ^{-1}$, berat kering brangkasan $\mathrm{ha}^{-1}$, berat kering biji $\tan ^{-1}$ berat kering biji ha ${ }^{-\mathbf{1}}$, berat 100 biji yang lebih tinggi dibandingkan dengan perlakuan yang lainya. Hal ini menunjukan bahwa semakin besar dosis pupuk yang diaplikasikan maka semakin besar unsur hara yang terkandung dalam tanah sehingga lebih banyak diserap oleh tanaman untuk pertumbuhannya. Hasil penelitian menunjukan bahwa hipotesis yang pertama (1) terbukti dengan peningkatan variabel pertumbuhan pada setiap perlakuan dosis pupuk NPK yang diberikan pada tanaman kacang hijau 
Murdaningsih: Pengaruh dosis pupuk npk mutiara terhadap pertumbuhan dan hasil tanaman kacang hijau (Phaseolus radiatus L.)

Sedangkan pada hipotesis ke-2 $(250 \mathrm{~kg}$ $\mathrm{ha}^{-1}$ ) tidak terbukti karena pada dosis pupuk NPK Mutiara $500 \mathrm{~kg} \mathrm{ha}^{-1}$ yang memberikan pertumbuhan tanaman kacang hijau yang baik. Hal ini menunjukkan bahwa hipotesis yang kedua (N2) tidak terbukti karena dosis tersebut belum mencukupi bagi pertumbuhan tanaman kacang hijau, karena kandungan hara yang terdapat pada pupuk NPK mutiara adalah nitrogen $16 \%$, posfor $16 \%$, dan kalium $16 \%$ sedangkan dosis pupuk NPK mutiara $250 \mathrm{~kg} \mathrm{ha}{ }^{-1}$ setara dengan $40 \mathrm{~kg} \mathrm{~N}, 40 \mathrm{~kg} \mathrm{P}, 40 \mathrm{~kg} \mathrm{~K}$, karena kebutuhan hara untuk tanaman kacang hijau $300 \mathrm{~kg} \mathrm{~N}, 100$ kg P dan 100 kg K (Marzuki, R. dan Soeprapto, H.S. 2007) sehingga dosis pupuk NPK mutiara $250 \mathrm{~kg} \mathrm{ha}^{-1}$ belum mencukupi kebutuhan tanaman kacang hijau. Jika dibandingkan dengan dosis pupuk NPK mutiara $500 \mathrm{~kg} \mathrm{ha}^{-1}$ setara dengan 80 $\mathrm{kg} \mathrm{N}, 80 \mathrm{~kg} \mathrm{P}, 80 \mathrm{~kg} \mathrm{~K}$ dosis tersebut masih memungkinkan ditingkatkan sesuai dengan kebutuhan hara tanaman kacang hijau. Hal ini membuktikan bahwa semakin banyak unsur hara yang diberikan pada tanaman kacang hijau maka semakin banyak pula jumlah unsur hara yang diserap tanaman guna mendukung pertumbuhan vegetatif dan generatif tanaman kacang hijau.

\section{Kesimpulan}

Dari hasil penelitian ini dapat disimpulkan bahwa :

1. Pemberian dosis pupuk NPK mutiara terhadap tanaman kacang hijau berpengaruh sangat nyata terhadap variabel tinggi tanaman 1,69\%, jumlah daun $3,23 \%$, luas daun, 6,50\%; jumlah polong $6,10 \%$, berat segar brangkasan $\tan ^{-1} 5,71 \%$, berat kering brangkasan $\tan ^{-}$ ${ }^{1} 6,25 \%$, berat kering brangkasan $\mathrm{ha}^{-1}$ $6,25 \%$, berat kering biji $\tan ^{-1} 5,41 \%$, berat kering biji ha ${ }^{-1} 5,41 \%$, berat 100 biji 7,25\%.

2. Pemberian pupuk NPK mutiara $500 \mathrm{~kg} / \mathrm{ha}$ terhadap tanaman kacang hijau menunjukan tinggi tanaman $27,75 \mathrm{~cm}$, 
Murdaningsih: Pengaruh dosis pupuk npk mutiara terhadap pertumbuhan dan hasil tanaman kacang hijau (Phaseolus radiatus L.)

jumlah daun 8 helai, luas daun 357,78

$\mathrm{cm}^{2}$, Jumlah polong 19,65, Berat segar

brangkasan $\tan ^{-1} 96,25$ gr, Berat kering

brangkasan $\tan ^{-1} 76,00$ gr, Berat kering

brangkasan $\mathrm{ha}^{-1} 19,00$ ton, Berat kering

biji $\tan ^{-1} 5,36$ gr, Berat kering biji ha ${ }^{-1}$

1,34 ton, Berat 100 biji 2,62 gr.

\section{Ucapan Terima Kasih}

Pada kesempatan ini penulis ingin mengucapkan terima kasih kepada semua pihak yang telah membantu dengan caranya masing-masing dalam melengkapi tulisan ini.

\section{DAFTAR PUSTAKA}

Adisarwanto,T. 2000. Meningkatkan Hasil Panen Kacang Tanah di Lahan Sawah dan di Lahan Kering. Penebar Swadaya. Jakarta. 88 Hal

Anonimous. 2013. Kacang Hijau. http://www.cnslearning.net/2013/03/ pengaruh-pemberian-pupuk-NPKterhadap-pertumbuhan-tanamankacang-hijau-vigna-radiata-L.html. Diakses tanggal 24/07/2013 jam 19:21.

Biro Pusat Statistik. 2013. Data Produksi Tanaman Kacang Hijau di Indonesia. BPS-Jakarta,Indonesia
Gomez, K. A dan Gomez, A. A. 1995. Prosedur statistik untuk penelitian pertanian. Jakarta: Universitas Indonesia press

Marzuki, R. dan Soeprapto, H.S. 2007. Bertanam Kacang Hijau. Penebar Swadaya, Jakarta.

Purnomo, dan P, Nainggolan. 2007. Pengaruh pupuk Majemuk NPK terhadap produksi dan kualitas buah jeruk keprok di Kabupaten Karo, Sumatra Utara. Laporan tahunan Balai Penelitian Tanah.

Purnomo dan R. Hartono. 2005. Kacang Hijau. Penebar .Swadaya. Jakarta

Rinsema, W. J. 2003.Pupuk dan Cara Pemupukan. Bhratara. Karya Aksana. Jakarta.

Rukmana, R. 2009. Bertanam kacang hijau. Penerbit Kanisius. Yogyakarta.

Saifudin. 2007. Petunjuk Penggunaan Pupuk. Penebar Swadaya. Jakarta

Sutedjo. 2002. Ilmu Tanah Pertanian. Pustaka Buana. Bandung.

Tage, D. E. 2012. Pengaruh pemberian mulsa jerami padi terhadap pertumbuhan dan hasil tanaman cabai besar (Capsicum annum L.) skripsi. Fakultas Pertanian

Wasis, B. dan N. Fathia. 2011. Pengaruh Pupuk NPK Terhadap Pertumbuhan Tanaman Semai Gmelina (Gmelina Arborea Roxb) pada media tanah bekas tambang emas(Tailing) jurnal sivikultur tropika vol 02. No. 01 hal 14-18. 